\title{
Facial fractures: Associated injuries and complications
}

\author{
J Grant Thomson MD FRCSC, Harvey C Brown MD FRCSC FACS, Rea A Brown MD FRCSC FACS, \\ David M Fleiszer MD FRCSC \\ Division of Plastic Surgery, Yale University School of Medicine, New Haven, Connecticut, USA, \\ Division of Plastic Surgery and Department of Surgery, McGill University, Montreal, Quebec
}

\begin{abstract}
JG Thomson, HC Brown, RA Brown, DM Fleiszer. Facial fractures: Associated injuries and complications. Can J Plast Surg 1994;1(4):160-165. The forces necessary to produce a facial fracture are often high enough to cause other severe, life-threatening injuries. Despite this knowledge, little is known about the frequency or nature of these injuries. A retrospective chart review was performed on 162 facial fracture patients for associated injuries and complications. These patients were divided into high velocity $(\mathrm{n}=95)$ and low-velocity $(\mathrm{n}=67)$ groups based on the mechanism of injury, and were compared with a group of 346 multiple trauma patients who did not sustain any facial fracture. Those patients involved in high-velocity accidents had a significantly higher proportion of multiple facial fractures $(40 \%)$, presence of associated injury (84\%), complication rate (38\%), mortality rate $(9.5 \%)$, mean hospital stay (45 days), and mean trauma score (20.1 \pm 1.3$)$ when compared with patients in low-velocity accidents $(10 \%, 12 \%, 10 \%, 4.3$ days and $4.7 \pm 0.6$, respectively). Although high-G facial bone fractures were more frequent in high-velocity accidents, high-G fractures were not an independent indicator of the severity of injury as measured by the trauma score. The most significant indicator of severity of injury was the mechanism of injury. Pulmonary (15\%), cerebral (11\%), septic (7\%), abdominal (7\%) and cardiac (2\%) complications after high-velocity injuries were more frequent than previously reported. Although cervical spine injury has traditionally been associated with facial fractures, the results of this study demonstrated that spinal injury can occur at any vertebral level, and was equal in frequency in patients with and without facial fractures. Statistical analysis of occupant restraint revealed that there was no significant difference between the numbers of patients wearing their seat belts (11) and those not using them (12), the proportions with high-G, low-G, or multiple facial fractures, the incidence of head injury or other associated injuries, the trauma score, and the times spent in the surgical intensive care unit and hospital. Although the lack of significance is probably attributable to the low documentation of seat belt use, the question of the efficacy of seat belts in preventing facial fractures and associated injuries is raised. Patients with facial

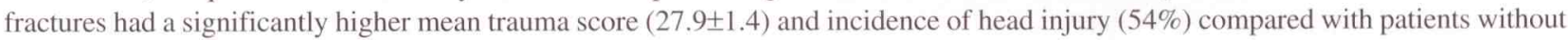
facial fractures $(23.2 \pm 0.7$ and $11 \%$, respectively). The surgical treatment of this group of facial fracture patients was analyzed.
\end{abstract}

Key Words: Complications, Facial fractures, Multiple trauma, Occupant restraint, Trauma score

\section{Fractures du visage : lésions et complications associées}

RÉSUMÉ : Les forces en jeu dans une fracture du visage sont souvent suffisantes pour provoquer d'autres lésions graves, voire à potentiel fatal. Même si ce fait est connu, on en sait relativement peu sur la fréquence ou la nature de ces lésions. Un examen rétrospectif des dossiers a été effectué sur 162 cas de fractures du visage pour y chercher la présence de lésions et de complications associées. Ces patients ont été divisés en deux groupes, soit «grande vélocité» $(\mathrm{N}=95)$ et «faible vélocité» $(\mathrm{N}=67)$ sur la base du mécanisme de la blessure, et ont été comparés avec un groupe de 346 polytraumatisés qui n'avaient pas subi de fractures au visage. Les patients impliqués dans les accidents à grande vélocité présentaient une proportion nettement plus élevée de fractures multiples du visage (40\%), de lésions associées ( $84 \%$ ), de taux de complications (38\%), de taux de mortalité $(9,5 \%)$, de séjours hospitaliers moyens (45 jours) et d'indice de traumatisme moyen $(20,1 \pm 1,3)$ en comparaison avec les patients impliqués dans des accidents à faible vélocité (10 \%,

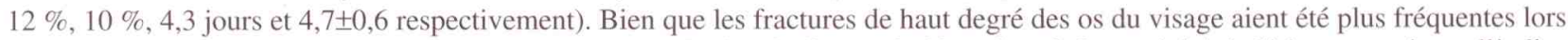
d'accidents à grande vélocité, ces fractures n'ont pas constitué un indicateur indépendant de la gravité de la lésion mesurée par l'indice de traumatisme. L'indicateur le plus important de la gravité de la lésion a été le mécanisme de cette dernière. Les complications pulmonaires $(15 \%)$, cérébrales $(11 \%)$, septiques $(7 \%)$, abdominales $(7 \%)$ et cardiaques $(2 \%)$, après des accidents à grande vélocité, ont été plus fréquentes que rapportées précédemment. Bien que les lésions de la moelle épinière aient habituellement été associées avec des fractures au visage, les résultats de cette étude ont démontré que les lésions de la moelle peuvent se produire au niveau de n'importe quelle vertèbre et que sa fréquence est égale, qu'il s'agisse de patients qui présentent ou non des fractures au visage. L'analyse statistique quant à l'emploi de la ceinture de sécurité n'a révélé aucune différence significative entre le nombre de patients qui portaient leur ceinture de sécurité (11) et ceux qui ne la portaient pas (12), entre les proportions de fractures au visage de faible ou de haut degré ou de lésions multiples, l'incidence de blessures à la tête ou autres blessures associées, l'indice de traumatisme et la durée du séjour à l'unité de soins intensifs et du séjour hospitalier. Bien que l'absence de portée relative soit probablement attribuable au fait que l'on dispose de peu de renseignements sur l'emploi de la ceinture de sécurité, il y a lieu de remettre en question l'efficacité des ceintures de sécurité à prévenir les fractures du visage et les lésions associées. Les patients porteurs de fractures au visage présentaient un indice de traumatisme moyen et une fréquence de blessures à la tête beaucoup plus élevés $(27,9 \pm 1,4$ et $54 \%$ ) en comparaison avec les patients qui n'avaient pas de fractures du visage $(23,2 \pm 0,7$ et $11 \%$ respectivement $)$. Le traitement chirurgical de ce groupe de patients atteints de fractures au visage a été analysé. 
$I^{n}$ the many years that have passed since the initial crude biomechanical studies by René LeFort involving facial fractures (1), our methods have become more sophisticated; not only have the force tolerance thresholds of the various bones of the face been determined (2), but the effects of biologic variations, load distribution and impulse time history have all been measured $(3,4)$. We live in an environment in which forces are commonly produced that exceed the level necessary to produce facial fractures (5). For example, facial injuries may occur in as many as $32 \%$ of all car crashes $(6,7)$. It is estimated that 625,000 hospital-treated facial injuries result from automobile accidents each year in the United States. Of these, 29,000 are severe facial fractures (8). Facial injury can also occur in up to two-thirds of victims of assault (9). At the same time severe associated injuries can be produced.

Previous studies have attempted to correlate the velocity of the trauma with the severity of the facial fracture and other injuries, but statistical analysis on this data has not been performed $(10,11)$. Furthermore, reports of complications resulting from trauma producing facial fractures are scarce. The first goal of this study was to identify patients with facial fractures who are at risk for associated life-threatening injuries and complications.

The presence of neck injury in association with facial fractures has traditionally received much attention $(10,11)$. Recent studies of trauma patients with multiple injuries suggest that thoracic and lumbar spine injuries are actually more frequent than cervical spine injury (12). The second goal was to determine if this was also true specifically in patients with facial fractures.

There is surprisingly little in the published medical literature regarding the role of occupant restraint in preventing facial fractures or associated trauma. The third goal of the present study was to determine the role of occupant restraint in reducing facial fractures and severe trauma.

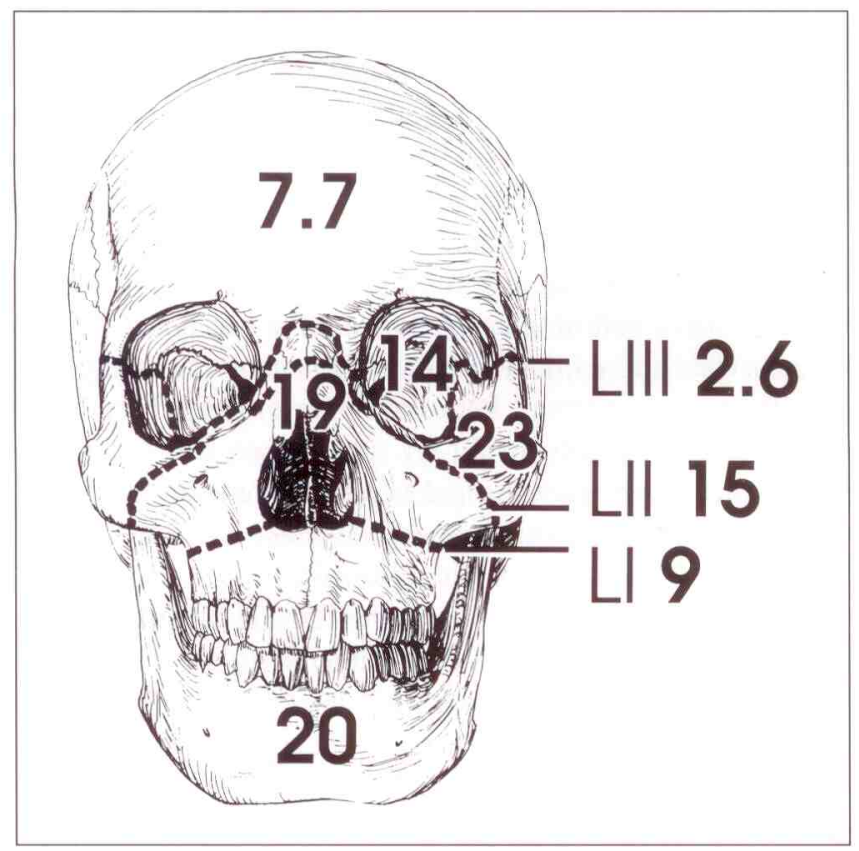

There are no published data comparing facial fracture patients with trauma patients who have not sustained a facial fracture. The fourth goal was to compare the severity of injury of facial fracture patients with other trauma patients involved in high-velocity accidents.

Finally, the surgical treatment of this group of facial fracture patients was analyzed.

\section{MATERIALS AND METHODS}

Ninety-five patients who sustained facial fractures in high-velocity accidents (defined as a motor vehicle accident or a fall from a height [10]) were recorded in the surgical intensive care unit (SICU) computer of the Montreal General Hospital for the years 1982 to 1986 . A low-velocity facial fracture (caused by a blow or a fall from a standing position) group was compiled from the medical records of 67 consecutive facial fracture patients admitted to the surgical wards of the Montreal General Hospital between July 1, 1985 and June 30, 1986. The relative numbers of high- and low-velocity patients cannot be compared since different time intervals were chosen. A total of 162 records were reviewed for demographic data, circumstances of injury, type of facial fractures, associated injuries, previous medical problems, surgery required, complications and length of hospital stay.

An additional 346 multiple trauma patients without facial fractures were obtained from the SICU computer. These were used as a control group. Their records were not extensively reviewed; however, the data available from the computer was used to compare mortality, head injury, spinal injury and trauma score of these patients with those parameters of facial fracture patients. The trauma score was calculated using the Injury Severity Score, which is based on the Abbreviated Injury Scale (13).

Statistical analysis was performed using the Student $t$ test, the chi-squared test and the Fisher exact test.

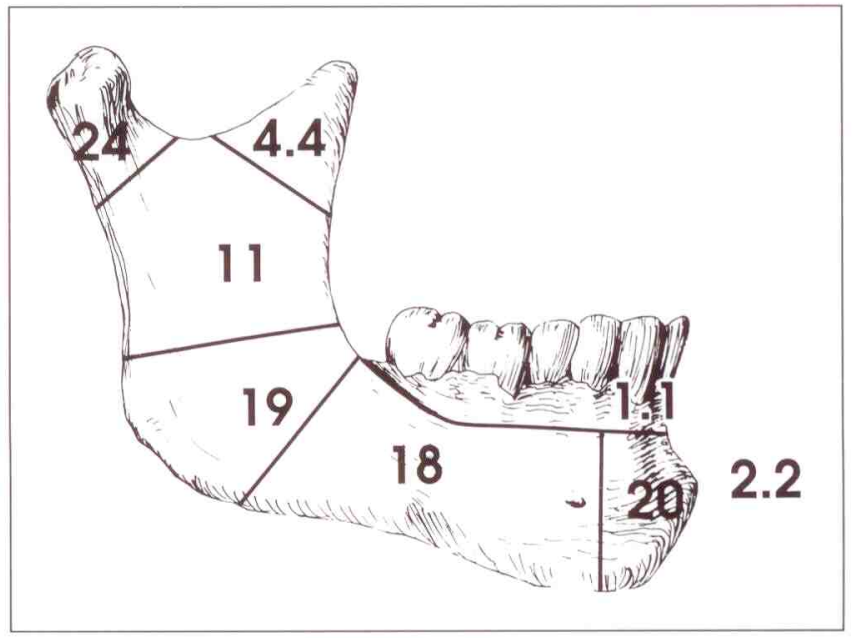

Figure 1) Left Frequency of facial fractures by location (\%). Low-G facial bones (zygoma, mandible and nose) are fractured more frequently than the high-G facial bones (orbit, frontal bone, maxilla)

Figure 2) Above Frequency of mandibular fractures by location (\%); 53 patients had mandibular fractures, 30 had more than one fracture site 


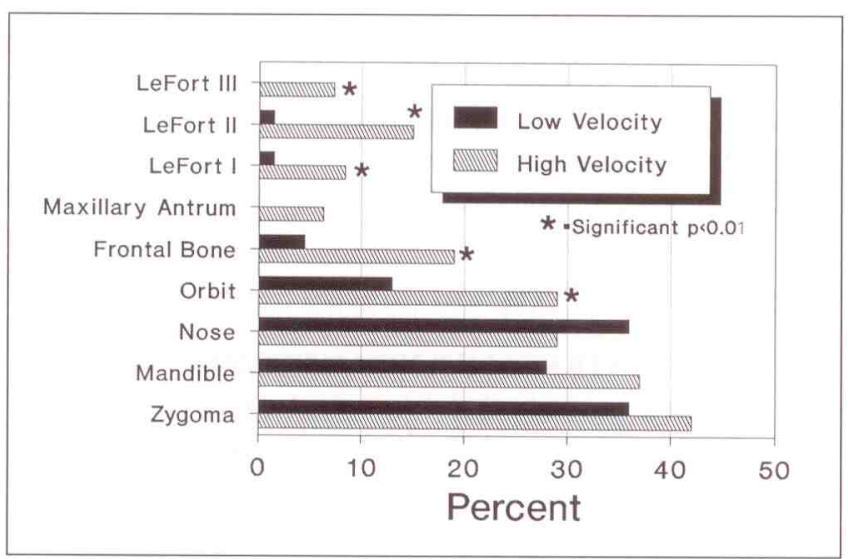

Figure 3) Specific fractures. High-velocity patients $(n=95)$ had significantly more orbital, frontal and LeFort fractures than low-velocity patients $(n=67)$

\section{RESULTS}

The mean age of the patients was 35 years, with a 3:1 male to female ratio. Since only admitted patients were included in this study, minimally displaced fractures requiring no treatment were not analyzed. In admitted patients, the most common facial fracture site was the zygoma, followed by the mandible, nose, orbit and maxilla (Figure 1).

In the mandible $(\mathrm{n}=53)$, the fracture sites in decreasing order of frequency were subcondylar, parasymphyseal, angle, body, ramus, symphysis, coronoid and alveolus (Figure 2 ). Twenty-three patients (43\%) had only one mandible fracture, three $(11 \%)$ had multiple fractures on the same side of the mandible, and $24(45 \%)$ had bilateral fractures. Of these $24,15(63 \%)$ involved a condyle and a site on the opposite side, seven (29\%) involved an angle and a site on the opposite side, and two (8\%) were bilateral parasymphyseal fractures.

In comparing groups based on the mechanism of injury, the proportions of high-velocity and low-velocity patients with zygoma, mandible and nasal fractures did not differ significantly. However, the high-velocity patients suffered significantly more fractures of the high-G facial bones (orbital, frontal, and LeFort fractures [2,10]) using chi-squared analysis $(\mathrm{P}<0.001)$ (Figure 3$)$. Forty percent of high-velocity patients presented with multiple facial fractures, compared with only $10 \%$ of low-velocity patients, a result which was also statistically significant $(\mathrm{P}<0.001)$. Open fractures were present in $28 \%$ and $16 \%$ of high- and low-velocity patients, respectively (not statistically significant). Associated injuries were present in $84 \%$ of patients in the high-velocity group, compared with only $12 \%$ of low-velocity injuries $\left(\mathrm{P}=8 \times 10^{-11}\right)$ (Figure 4).

Head injury occurred in $45 \%$ of high-velocity patients, and included skull fracture (26), concussion (19), cerebral contusion (15), intracranial hemorrhage (seven) and brain stem injury (two).

The chest was injured in $42 \%$ of high-velocity patients, and included skull fracture (22), pulmonary contusion (14), pneumothorax (10), hemothorax (five), cardiac contusion (four) and sternum fracture (two).

Thirteen percent of high-velocity patients incurred ab-

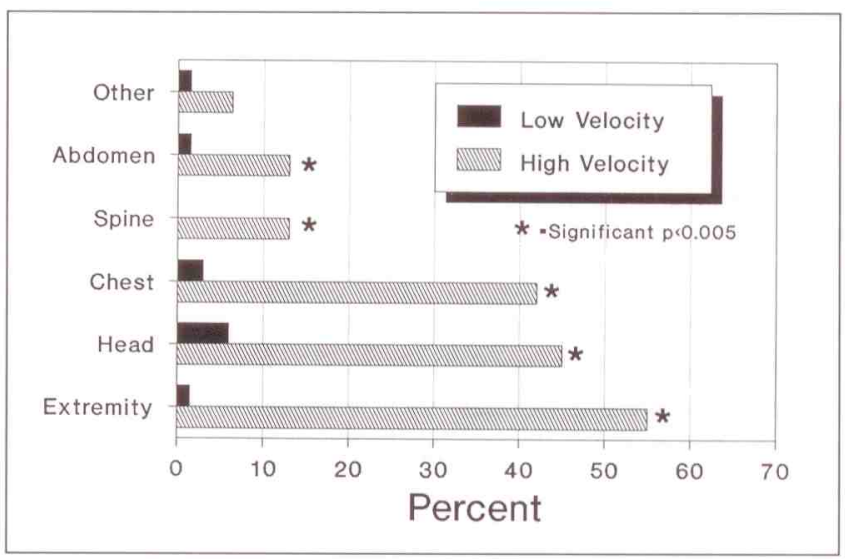

Figure 4) Associated injuries were more common in high-velocity patients

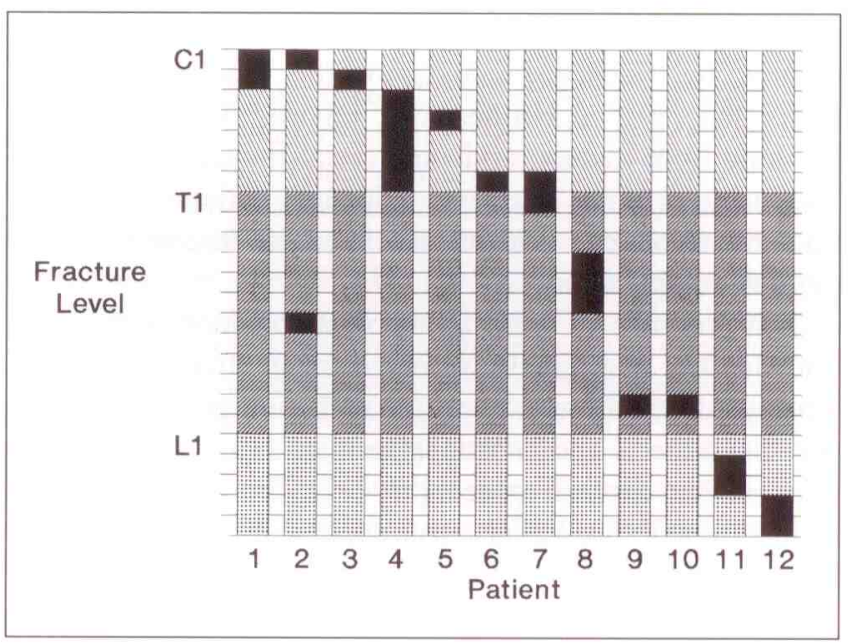

Figure 5) Pattern of spinal injury. Seven patients had cervical spine injury, and seven had an injury below $C_{7}$

dominal injury, including the liver (five), kidney (four), left hemidiaphragm (two), pancreas (one), spleen (one), adrenal (one) and colon (one).

Extremity injury was present in $55 \%$ of patients in the high-velocity group, and the number of patients with lower extremity injuries (74) were almost twice that of upper extremity injuries $(43)(\mathrm{P}<0.001)$.

Twelve patients had spinal fractures (13\% of high-velocity trauma) (Figure 5). Only the patient with fractures from $\mathrm{C}_{3}$ to $\mathrm{C}_{7}$ had a neurological deficit, and he was quadriplegic. One cervical spine injury was missed because the $\mathrm{x}$-ray was initially read as normal. Persistent pain prompted repeat $\mathrm{x}$ rays and the diagnosis of $\mathrm{C}_{1}-\mathrm{C}_{2}$ subluxation was made two weeks later. Seven patients had a cervical spine injury, but an equal number had a vertebral injury below $\mathrm{C}_{7}$ (one patient had both cervical and thoracic injuries).

The overall complication rate was $38 \%$ in the high-velocity group and $10 \%$ in the low-velocity group $\left(\mathrm{P}=5 \times 10^{-5}\right)$. Serious, life-threatening complications occurred almost exclusively in the high-velocity patients, and included pulmonary $(15 \%)$, cerebral $(11 \%)$, septic $(7 \%)$, abdominal $(7 \%)$ and cardiac (2\%). The high- and low-velocity groups had similar 


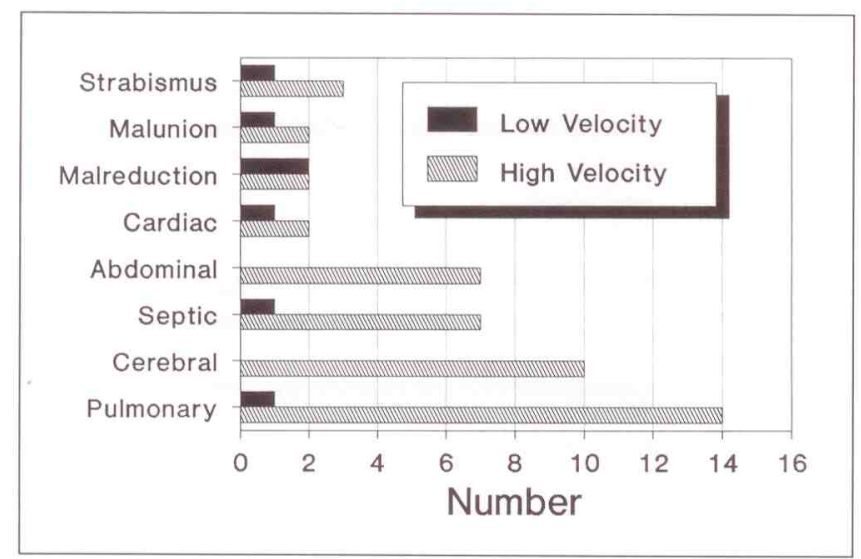

Figure 6) Life-threatening complications were more frequent after highvelocity injuries

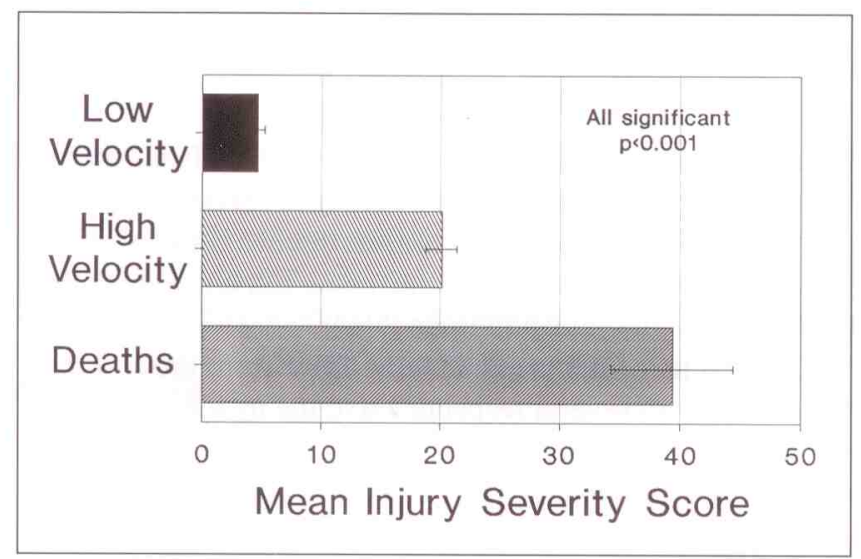

Figure 8) Trauma score was measured using the Injury Severity Score. The mean trauma score of high-velocity patients was significantly higher than that of low-velocity patients. The nine patients who died had a mean trauma score twice that of the other high-velocity patients. Error bars represent $\pm S E M$

numbers of complications directly related to the facial surgery such as malunion, malreduction and strabismus ( 2 to 3\%) (Figure 6).

Twelve percent of high-velocity patients required a tracheostomy. There were no emergency crycothyroidotomies and all tracheostomies were done electively within two weeks of admission in the operating room. Airway obstruction was not a cause of death in this series.

Most deaths were secondary to cerebral injury (five), but two patients died from pulmonary sepsis. The high-velocity group had a death rate of almost $10 \%$. There were no deaths in the low-velocity group (Figure 7).

The mean hospital stay of high-velocity patients was $45 \pm 12$ days (mean \pm SEM), which was significantly different from that of low-velocity patients $(4.34 \pm 0.53$ days, $\mathrm{P})<0.005$ using the Student $t$ test.

The mean trauma score of high-velocity patients (20.1 \pm 1.3$)$ was significantly higher than that of low-velocity patents $\left(4.7 \pm 0.6, \mathrm{P}=5 \times 10^{-14}\right)$. All nine deaths occurred in the high-velocity group, and their mean trauma score (39.4 \pm 5.1$)$ was twice that of the high-velocity group itself $\left(\mathrm{P}<2 \times 10^{-7}\right)$ (Figure 8 ). In the high-velocity group, the trauma score in

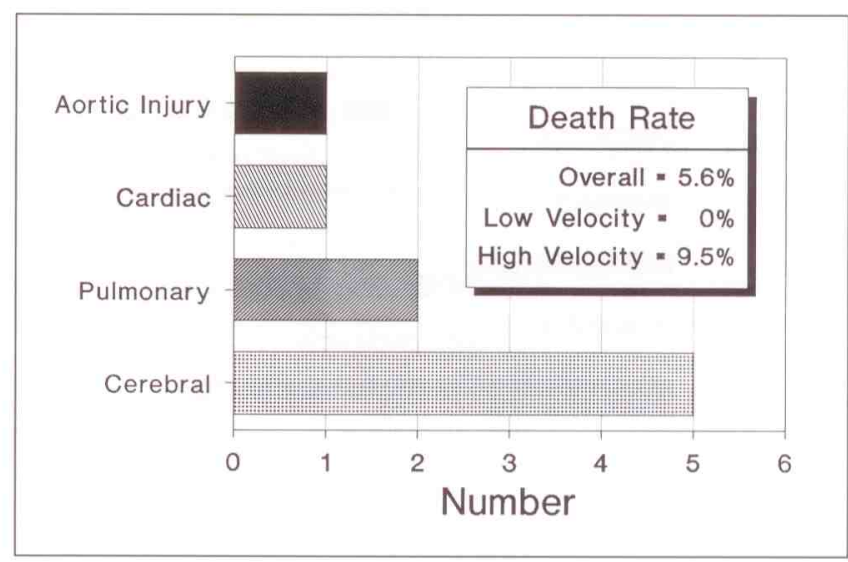

Figure 7) Cause of death. The most common cause was cerebral injury

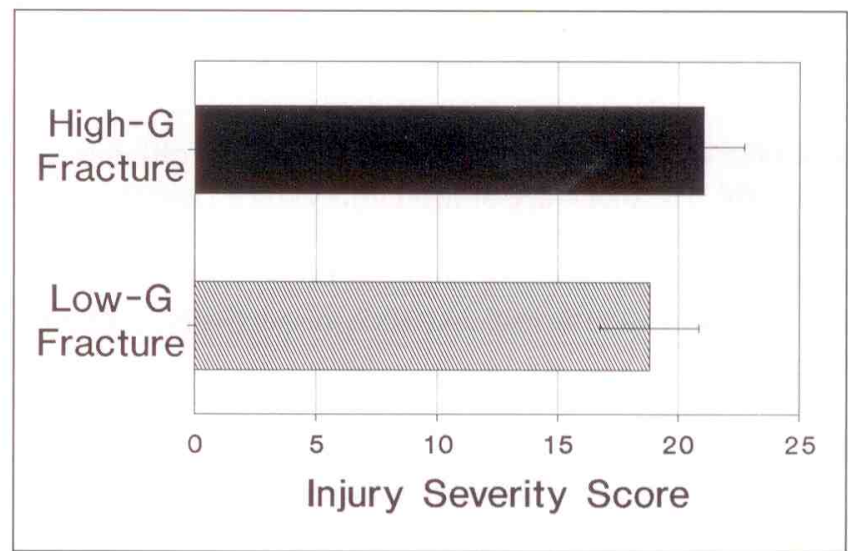

Figure 9) Trauma score in high velocity injuries. There was no significant difference in trauma score between patients with high- $G(n=51)$ and low- $G(n=44)$ fractures. The type of fracture was not a good predictor of the severity of injury

patients with fractured bones requiring high-G forces $(21.7 \pm 2.1, \mathrm{n}=51)$ did not differ significantly from that in patients with fractures that required low-G forces $(18.4 \pm 1.5$, $\mathrm{n}=44$ ) (Figure 9). Four patients with high-G fractures died, while five low-G patients died (not statistically significant).

The 84 motor vehicle accidents included four all-terrainvehicle/snowmobile, 10 motorcycle, 14 pedestrian and 56 automobile occupant injuries. Information about occupant restraint was available in only 23 of 56 cases. The 11 patients who were wearing their seat belts at the time of injury were compared with the 12 patients in the no-seat belt group. There were no statistically significant differences in the proportion of high-G and low-G fractures, the number of patients with multiple facial fractures, the times in the SICU and hospital, or the mean trauma score. Spine and extremity injuries were increased in the restrained group, and this data approached statistical significance using the Fisher exact test $(\mathrm{P}=0.09$ and $\mathrm{P}=0.07$, respectively). Likewise, the proportion with head injury was increased in the unrestrained group, and this also approached statistical significance ( $\mathrm{P}=0.12$ ) (Figure 10).

Comparing SICU patients with and without facial fractures, neither the proportion with spinal injuries (15\% versus 


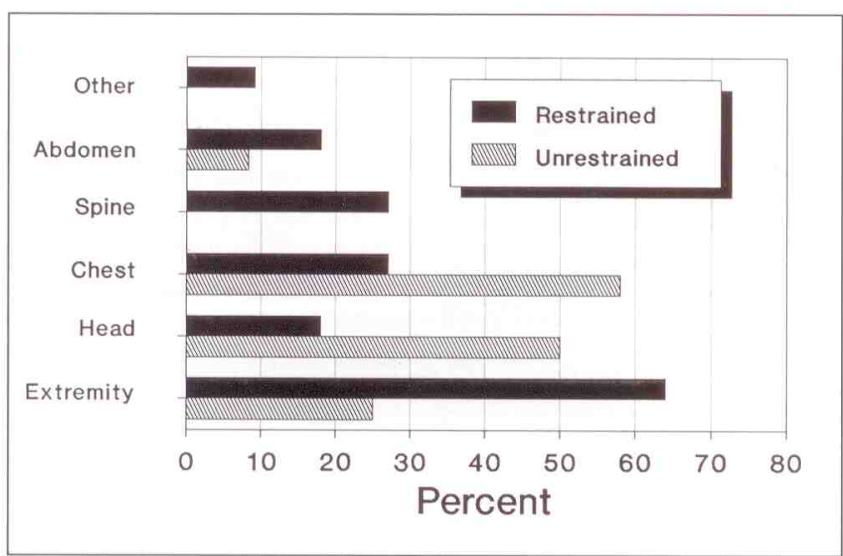

Figure 10) Associated injuries and seat belts. Frequency of head injury was reduced in restrained occupants $(n=11)$, but the same group had a higher frequency of spine and extremity injuries, compared with unrestrained occupants $(n=12)$. These results approached statistical signicance $(P=0.12,0.09$ and 0.07 , respectively)

$19 \%$ ) nor the mortality rate (11\% versus $15 \%$ ) differed significantly. The incidence of head injury $(54 \%)$ and the mean trauma score $(27.9 \pm 1.4)$ were significantly increased in patients with facial fractures compared with patients without facial fractures ( $11 \%$ and $23.2 \pm 0.7$, respectively, $\mathrm{P}<0.001$ ) (Figure 11).

\section{Surgical treatment of facial fractures}

None of the low-velocity patients required surgery on any body region other than the face. High-velocity patients underwent surgery on the chest in $4 \%$, the abdomen in $7 \%$, the cranium in $8 \%$, the extremities in $32 \%$ and the face in $71 \%$.

Fifty percent of nasal fractures were minimally displaced and required no treatment. The remainder underwent closed reduction. Similarly, only $48 \%$ of blowout fractures were explored. All of these were repaired with a silastic shim. Seventy-six percent of zygoma fractures required surgery. Forty-six percent of these were unstable and required open reduction and internal fixation while Gillies' reduction was sufficient in $54 \%$. Mandible fractures were treated with a variety of techniques, including jaw diet, open reduction and internal fixation, mandibular-maxillary fixation, and external fixation, depending on the type of fracture. The majority of LeFort fractures were treated with a combination of open reduction and internal fixation, mandibular-maxillary fixation, and/or suspension wires.

\section{DISCUSSION}

A previous study of 1020 facial fractures reported the incidence of associated injuries to range from $14 \%$ in lowvelocity trauma to $63 \%$ in high-velocity trauma patients (10). In the latter group, the injury sites included the central nervous system $(21.2 \%)$, the lungs $(13 \%)$ and the abdomen $(6.7 \%)$. This same study demonstrated an increased risk of associated injuries in patients who fractured facial bones with a high resistance to impact (high-G facial bones). They concluded that both the mechanism of injury and the type of facial bone fracture were good

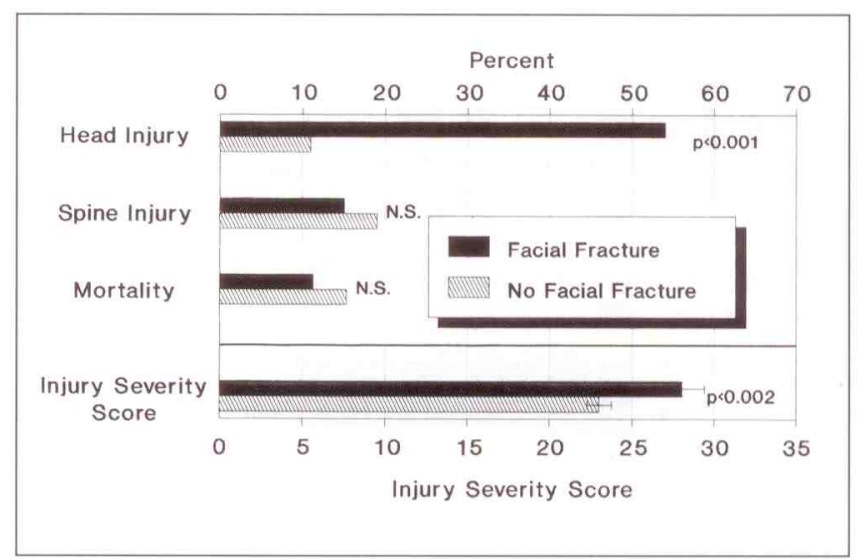

Figure 11) Comparison with and without facial fractures. Patients with facial fractures $(n=80)$ had a higher frequency of head injury and a higher trauma score than patients without facial fractures $(n=346)$

predictors of severity of injury. Statistical analysis was not reported in their paper. In another study involving only highvelocity trauma, associated injuries occurred in 59\% (11). The areas injured included the head (54\%), extremities $(32 \%)$, chest $(9 \%)$ and abdomen $(5 \%)$.

The results of the present study differ from those of previous studies in several respects. First, the incidence of associated injury in high-velocity trauma (84\%) is higher than previously reported, probably due to a higher incidence of extremity and head injury. Separating facial fracture patients into groups based on the mechanism of injury resulted in a statistically significant difference in the proportion with multiple facial fractures, the proportion with high-G fractures, the presence of associated injury, the complication rate, the mortality rate, the duration of hospital stay, and the mean trauma score. Thus, the mechanism of injury is a good predictor of the severity of injury. However, in the high-velocity group, there was no significant difference in the trauma scores of patients with high-G facial bone fractures and those without. The power of this assertion is $65 \%$, indicating that the type of bone that is fractured is not a good indicator of the severity of injury. This may be explained by the fact that the force thresholds for fracture of any of the facial bones are easily surpassed in high-velocity trauma, and thus high-G fractures may be produced regardless of the violence of the impact.

Previously, complications in facial fracture patients have been poorly documented. The most common complication has been reported as 'fever over $101^{\circ} \mathrm{F}$ ' $(8.3 \%)$, followed by pulmonary complications $(1.6 \%)$ and local infections $(1.6 \%)$ (14). The death rate ranges from $0.75 \%$ to $2.7 \%(10,11,14)$. The present data have demonstrated that complications occurred in $38 \%$ of high-velocity patients. Although pulmonary complications (15\%) were more frequent than cerebral complications $(11 \%)$, more patients died from cerebral injuries. The high-velocity patients had a mortality rate of $9.5 \%$, also higher than previously reported.

The incidence of neck injury has been reported to be as high as $4 \%$ in patients with facial fractures $(10,11)$. Thoracic 
and lumbar spine fractures also occur (10), but these injuries have received little attention (15). Our data have shown that patients with facial fractures have a high risk of spinal injury both above and below $\mathrm{C}_{7}$. Spinal injuries occur in patients with facial fractures at the same rate as the average high-velocity trauma patient.

There is a general agreement that occupant restraint reduces injury severity and mortality (16-20). However, the effectiveness of seat belts in preventing facial injury has not been definitively demonstrated in controlled studies. Some reports have correlated the introduction of seat belt legislation in their area with a fall in the numbers of facial fractures and spinal cord injuries (21), but when statistical analysis is performed, these changes may not be significant (22). While some authors claim that occupant restraint reduces facial injury by $25 \%(7,23)$, and others report remarkably few injuries in belted occupants $(24,25)$, it has been clearly demonstrated in studies involving car crash testing and field accident data that facial injury can occur in up to $92 \%$ of fully restrained drivers $(6,8,26,27)$.

Seat belt legislation is effective in our area in encouraging seat belt use, but it may partially interfere with data acquisition by making patients hesitant to admit that they were unrestrained. In patients for whom information was available

\section{REFERENCES}

1 LeFort R. Étude expérimentale sur les fractures de la mâchoire supérieure. Rev chir de Paris 1901;23:208-27, 360-79, 479-507.

2. Swearingen JJ. Tolerances of the human face to crash impact. Oklahoma City, Oklahoma: Office of Aviation Medicine, Federal Aviation Agency, Civil Aeromedical Research Institute. 1965;1-126.

3. Nahum AM, Gatts JD, Gadd CW, Danforth J. Impact tolerance of the skull and face. Proceedings of the 12th STAPP Car Crash Conference: Society of Automotive Engineers, 1968;302-16.

4. Nahum, AM. The biomechanics of maxillofacial trauma. Clin Plastic Surg 1975;2:59-64.

5. Hoehn RJ. Facial injury. Surg Clin NA 1973;53:1479-508.

6. Haeusler, R. Facial injury to vehicle occupants associated with traffic crashes. The engineer's viewpoint. Clin Plast Surg 1975;2:47-51

7. Huelke DF, Compton CP. Facial injuries in automobile crashes. J Oral Maxillofac Surg 1983,41:241-4.

8. Karlson TR. The incidence of hospital-treated facial injuries from vehicles. J Trauma 1982;22:303-10.

9. Shepherd JP, Shapland M, Pearce NX, Scully C. Pattern, severity and aetiology of injuries in victims of assault. J Roy Soc Med 1990;83:75-8.

10. Luce EA, Tubb TD, Moore AM. Review of 1,000 major facial fractures and associated injuries. Plast Reconstr Surg 1979;63:26-30.

11. Schultz RC. Facial injuries from automobile accidents: A study of 400 consecutive cases. Plast Reconstr Surg 1967;40:415-25.

12. Pal JM, Mulder DS, Brown RA, Fleiszer DM. Assessing multiple trauma: Is the cervical spine enough? J Trauma 1988;28:1282-4.

13. Committee on Injury Scaling: Abbreviated Injury Scale, 1985 Revision. Des Plaines, Illinois: American Association for Automotive Medicine.

14. Gwyn PP, Carraway JH, Horton CE, Adamson JE, Mladick RA. Facial fractures - associated injuries and complications. Plast Reconstr Surg 1971;47:225-30.

15. Haisová L, Krámová I. Facial bone fractures associated with cervical spine injuries. Oral Surg 1970;30:742-8. regarding occupant restraint, there were equal numbers of restrained and unrestrained facial fracture patients. Furthermore, restrained and unrestrained occupants had nonsignificant differences in the proportions with high-G and low-G fractures, multiple facial fractures,trauma scores and times spent in the SICU and hospital wards. However, spine and extremity injuries were more common in restrained occupants, and head injury was more common in unrestrained occupants. These latter differences approached statistical significance ( $\mathrm{P}=0.09,0.07$, and 0.12 , respectively). The low sample size makes it difficult to draw definite conclusions; nevertheless, these data raise the question of the efficacy of seatbelts in preventing facial fractures and associated injuries, and illustrates the difficulty in obtaining data of this type, the importance of statistical analysis and the need for further controlled studies.

Finally, multiple trauma patients with facial fractures have a higher incidence of head injury and have a higher trauma score than the average high-velocity trauma patient, while the proportions with spinal injuries and the mortality rates are similar in the two groups. These results have not been previously reported. Physicians treating these severely injured patients should be aware of the associated injuries and possible complications.

16. Huelke DF, Sherman HW. Automobile accident studies of maxillofacial injuries. Clin Plastic Surg 1975;2:53-8.

17. Simpson HM, Warren RA. Seat belts and traffic safety: The Canadian experience. In: Green RN, Petrucelli E, eds. Proceedings International Symposium on Occupant Restraint, Toronto, Ontario, Canada. Morton Grove, Illinois: American Association for Automotive Medicine. 1981;73-83.

18. Campbell BJ. Safety belt injury reduction related to crash severity and front seated position. J Trauma 1987;27:733-9.

19. Evans L. Fatality risk reduction from safety belt use. J Trauma 1987;27:746-9.

20. Petrucelli E. Seat belt laws: The New York experience - preliminary data and some observations. J Trauma 1987;27:706-10.

21. Reynolds JR. Late complications vs. method of treatment in a large series of mid-facial fractures. Plast Reconstr Surg 1978;61:871-5

22. Thomas $\mathbf{J}$. Road traffic accidents before and after seatbelt legislation - study in a district general hospital. J Roy Soc Med 1990;83:79-81.

23. Huelke DF. Effectiveness of occupant restraint in reducing serious injuries and fatalities. In: Green RN, Petrucelli E, eds. Proceedings International Symposium on Occupant Restraint, Toronto, Ontario, Canada. Morton Grove, Illinois: American Association for Automotive Medicine. 1981;33-8.

24. Nelson WD. Lap-shoulder restraint effectiveness in the United States. Detroit, Michigan: Society of Automotive Engineers, Automotive Engineering Congress. Paper 710077. 1971:1-8.

25. Huelke DF, Sherman HW. Seat belt effectiveness: Case examples from real-world crash investigations. J Trauma 1987;27:750-3.

26. Gallup BA, Newman JA. The assessment of facial injury to fully restrained drivers through full-scale car crash testing. J Trauma 1987;27:711-8.

27. McCoy GF, Johnstone RA, Nelson IW, Duthie RB. Facial injuries to restrained drivers caused by steering wheels [letter]. Lancet $1988 ; \mathrm{ii}: 456$. 